\title{
Downregulation of both mismatch repair and non-homologous end-joining pathways in hypoxic brain tumour cell lines
}

\author{
Sophie Cowman ${ }^{1,2}$, Barry Pizer ${ }^{3}$, Violaine See ${ }^{\text {Corresp. } 1}$ \\ 1 Institute of Systems, Molecular and Integrative Biology, Department of Molecular Physiology and Cell Signalling, University of Liverpool, LIVERPOOL, \\ Merseyside, United Kingdom \\ 2 Department of Pharmacology and Toxicology, College of Pharmacy, University of Utah, Salt-Lake-City, Utah, United States \\ 3 Paediatric Oncology, Alder Hey Children's NHS Foundation Trust, Liverpool, Merseyside, United Kingdom \\ Corresponding Author: Violaine See \\ Email address: violaine@liverpool.ac.uk
}

Glioblastoma, a grade IV astrocytoma, has a poor survival rate in part due to ineffective treatment options available. These tumours are heterogeneous with areas of low oxygen levels, termed hypoxic regions. Many intra-cellular signalling pathways, including DNA repair, can be altered by hypoxia. Since DNA damage induction and subsequent activation of DNA repair mechanisms is the cornerstone of glioblastoma treatment, alterations to DNA repair mechanisms could have a direct influence on treatment success. Our aim was to elucidate the impact of chronic hypoxia on DNA repair gene expression in a range of glioblastoma cell lines. We adopted a NanoString transcriptomic approach to examine the expression of 180 DNA repair-related genes in four classical glioblastoma cell lines (U87MG, U251-MG, D566-MG, T98G) exposed to 5 days of normoxia $\left(21 \% \mathrm{O}_{2}\right)$, moderate $(1 \%$ $\left.\mathrm{O}_{2}\right)$ or severe $\left(0.1 \% \mathrm{O}_{2}\right)$ hypoxia. We observed altered gene expression in several DNA repair pathways including homologous recombination repair, non-homologous end-joining and mismatch repair, with hypoxia primarily resulting in downregulation of gene expression. The extent of gene expression changes was dependent on hypoxic severity. Some, but not all, of these downregulations were directly under the control of HIF activity. For example, the downregulation of LIG4, a key component of non-homologous endjoining, was reversed upon inhibition of the hypoxia-inducible factor (HIF). In contrast, the downregulation of the mismatch repair gene, PMS2, was not affected by HIF inhibition. This suggests that numerous molecular mechanisms lead to hypoxia-induced reprogramming of the transcriptional landscape of DNA repair. Whilst the global impact of hypoxia on DNA repair gene expression is likely to lead to genomic instability, tumorigenesis and reduced sensitivity to anti-cancer treatment, treatment re-sensitising might require additional approaches to a simple HIF inhibition. 
Downregulation of both mismatch repair and non-homologous end-joining pathways in hypoxic brain tumour cell lines

Sophie Cowman ${ }^{1,2}$, Barry Pizer ${ }^{3}$ and Violaine Sée ${ }^{1^{*}}$

\author{
Affiliations: \\ 1 University of Liverpool, Institute of Systems, Molecular and Integrative Biology, Department of Molecular \\ Physiology and Cell Signalling; Centre for Cell Imaging, Liverpool, UK \\ ${ }^{2}$ Current address: University of Utah, Department of Pharmacology and Toxicology, College of \\ Pharmacy, Salt Lake City, Utah, USA \\ ${ }^{3}$ Alder Hey Children's NHS Foundation Trust, Liverpool, UK \\ E-mail addresses for all authors: \\ Sophie Cowman: sophie.cowman@utah.edu \\ Barry Pizer: Barry.Pizer@alderhey.nhs.uk \\ *Corresponding author: Violaine See: violaine@liverpool.ac.uk \\ Tel: +44 (0)151 7954598 or 4454; Fax: +44 (0)151 7954404
}

Running title: Global alteration of DNA repair gene expression by hypoxia 


\section{Abstract}

2 Glioblastoma, a grade IV astrocytoma, has a poor survival rate in part due to ineffective treatment options

3 available. These tumours are heterogeneous with areas of low oxygen levels, termed hypoxic regions.

4 Many intra-cellular signalling pathways, including DNA repair, can be altered by hypoxia. Since DNA

5 damage induction and subsequent activation of DNA repair mechanisms is the cornerstone of

6 glioblastoma treatment, alterations to DNA repair mechanisms could have a direct influence on treatment

7 success. Our aim was to elucidate the impact of chronic hypoxia on DNA repair gene expression in a

8 range of glioblastoma cell lines. We adopted a NanoString transcriptomic approach to examine the

9 expression of 180 DNA repair related genes in four classical glioblastoma cell lines (U87-MG, U251-MG,

10 D566-MG, T98G) exposed to 5 days of normoxia $\left(21 \% \mathrm{O}_{2}\right)$, moderate $\left(1 \% \mathrm{O}_{2}\right)$ or severe $\left(0.1 \% \mathrm{O}_{2}\right)$

11 hypoxia. We observed altered gene expression in several DNA repair pathways including homologous

12 recombination repair, non-homologous end-joining and mismatch repair, with hypoxia primarily resulting

13 in downregulation of gene expression. The extent of gene expression changes was dependent on hypoxic

14 severity. Some, but not all, of these downregulations were directly under the control of HIF activity. For

15 example, the downregulation of LIG4, a key component of non-homologous end-joining, was reversed

16 upon inhibition of the hypoxia inducible factor (HIF). In contrast, the downregulation of the mismatch

17 repair gene, PMS2, was not affected by HIF inhibition. This suggests that numerous molecular mechanisms lead to hypoxia-induced reprogramming of the transcriptional landscape of DNA repair. Whilst the global impact of hypoxia on DNA repair gene expression is likely to lead to genomic instability, tumorigenesis and reduced sensitivity to anti-cancer treatment, treatment re-ssensitising might require 21 additional approaches to a simple HIF inhibition. 


\section{Introduction}

25 Glioblastoma (GBM) is a highly aggressive and infiltrative grade IV astrocytoma, the most common

26 malignant brain tumour in adults (Dolecek et al., 2012). Survival rates remain low partly due to the limited

27 treatment options available. Standard protocols involve initial resection of the tumour mass, which is

28 challenging due to the un-definable tumour border. Therefore, post-surgery radiotherapy and

29 chemotherapy are essential for disease control. Radiotherapy is typically delivered as multiple fractions

30 with a 60 Gy total dose (Chang et al., 1983; Omuro and DeAngelis, 2013). Temozolomide an alkylating

31 agent, is the sole chemotherapeutic agent used for GBM in the U.K. Using temozolomide as an adjuvant

32 increases mean survival rate compared to radiotherapy alone (Athanassiou et al., 2005). However, in

33 order for temozolomide to be effective, the $\mathrm{O}^{6}$-methylguanine-DNA methyltransferase (MGMT) gene must

34 be silenced, leaving non-silenced patients with even fewer treatment options (Brada et al., 1999;

35 Glassner et al., 1999; Esteller, Garcia-Foncillas and Andion, 2000; Hegi. et al., 2005). Alternative

36 therapies currently under investigation include PARP inhibitors, and vaccine-based therapies (Zhang et

37 al., 2004; Cheng et al., 2005; Liau et al., 2018). Despite many attempts to improve GBM outcome,

38 survival over five years is close to zero, with numerous barriers to successful GBM treatment still

39 remaining. One such barrier is tumour hypoxia, which can negatively influence the effectiveness of both

40 radiotherapy and temozolomide treatment and is associated with poor patient survival for GBM and for

41 many other solid tumours (Marampon et al., 2014; Ge et al., 2018).

42 Spatial and temporal heterogeneity of oxygen availability arises due to the formation of aberrant

43 vasculature, prone to leaks and bursts, and large diffusion distances between oxygen rich vessels and

44 tumour cells (Vaupel, Rallinoâ and Okunieff, 1989; Vaupel and Harrison, 2004). In the brain, healthy

45 oxygen levels range from $5-8 \%$, yet in GBM, cells are exposed to as little as $0.5 \%$ to $3 \% \mathrm{O}_{2}$ (Rampling et

46 al., 1994), defined as pathophysiological hypoxia. In terms of reducing anti-cancer therapy effectiveness,

47 hypoxia can alter DNA repair mechanism through epigenetic modifications, transcription and translation

48 alterations, and post-translational modifications of DNA repair proteins (reviewed in Scanlon and Glazer,

49 2015). DNA damage response is the cornerstone of GBM therapy: both radiotherapy and temozolomide

50 target DNA, causing high levels of DNA damage which overwhelms repair mechanisms leading to the

Peer] reviewing PDF | (2020:10:54060:2:0:NEW 15 Mar 2021) 
51 induction of apoptosis via p53 activation (Banin et al., 1998; Canman et al., 1998; Epstein et al., 2001;

52 Turenne et al., 2001; Saito et al., 2002).

53

54

55

56

57

58

59

60

61

62

63

64

65

66

67

68

69

70

71

72

73

74

75

76

77

78

Hypoxia has been shown to transcriptionally downregulate homologous recombination repair (HRR) components leading to reduced HRR capacity (Bindra et al., 2004, 2005; Meng et al., 2005; Bindra and Glazer, 2007; Bindra, Crosby and Glazer, 2007; Chan et al., 2008). Also, components of nucleotide excision repair are downregulated by hypoxia even after periods of reoxygenation (Dudás et al., 2014). In addition, we previously showed that NBN and MRE11, members of a DNA double strand break recognition complex are downregulated by chronic but not acute hypoxia (Cowman et al., 2019). These studies exemplify the fact that hypoxia can influence DNA repair, however, there has been little exploration of the global impact of long-term hypoxia on DNA repair gene expression in glioblastoma. We adopted a NanoString transcriptomic approach to assess the impact of chronic hypoxia on DNA repair genes in glioblastoma cell lines. We found that hypoxia specifically affects mismatch repair (MMR), non-homologous end-joining (NHEJ) and homologous recombination repair (HRR). Additionally, we provide evidence that the hypoxia inducible factor (HIF) play a role in downregulation of some, but not all, key DNA repair genes. Downregulation of DNA repair genes by hypoxia will have significant clinical impact for cancer management and should be considered when designing new treatment methods and protocols.

\section{Materials and Methods}

Reagents: Cell culture reagents were from Gibco Life Technologies and Foetal Calf Serum from Harlam Seralab (UK). Acriflavin was purchased from Sigma Aldrich. $\beta$-Actin (Ab8226), PMS2 (Ab110638) and

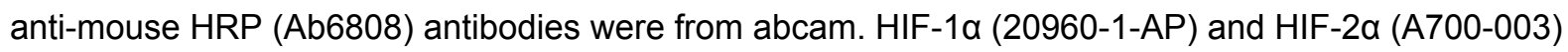
were from Bethyl. Anti-rabbit HRP (7074S) antibody was from Cell Signalling.

Cell Culture: U87-MG (p53 wild type, MGMT methylated) and T98G (p53 mutant, MGMT unmethylated) were purchased from ATCC. U251-MG (p53 mutant, MGMT methylated) were purchased from CLS. D566-MG cells (p53 mutant, MGMT unknown) were a kind gift from Prof. DD Bigner (Duke University, USA). U87-MG and T98G were cultured in modified Eagle's Medium (EMEM) with 10\% FCS, $1 \%$ Sodium 
79 pyruvate. D566-MG and U251-MG were cultured using EMEM, 10\% FCS, 1\% sodium pyruvate and 1\% 80 non-essential amino acids. Cells were maintained at $37^{\circ} \mathrm{C}$ in $5 \% \mathrm{CO}_{2}$. For hypoxic experiments, cells 81 were incubated in a Don Whitley H35 Hypoxystation for $1 \% \mathrm{O}_{2}$ or a New Brunswick Galaxy $48 \mathrm{R}$ incubator 82 for $0.1 \% \mathrm{O}_{2}$. Cells were routinely tested for mycoplasma infection.

83

84 NanoString Assay: Cells were cultured in $6 \mathrm{~cm}$ dishes for 5 days at $21 \%, 1 \%$ or $0.1 \% \mathrm{O}_{2}$. RNA was extracted using High Pure RNA Extraction kit (Roche). 100 ng of total RNA was used in the NanoString assay. The expression of 180 DNA repair genes, plus 12 housekeeping genes, were assessed using the NanoString nCounter Vantage ${ }^{\mathrm{TM}}$ RNA Panel for DNA Damage and Repair (LBL-10250-03) following the manufacturer's protocol. Analysis of the NanoString data was conducted using nSolver ${ }^{\mathrm{TM}}$ Analysis Software (3.0) with nCounter® Advanced Analysis plug-in (2.0.115). Data are available at https://www.ncbi.nlm.nih.gov/geo/query/acc.cgi?acc=GSE139250 and in supplemental dataset 1.

Real Time PCR: RNA was extracted using High Pure RNA Extraction kit (Roche). Reverse transcription was conducted using SuperScript $®$ VILO (Invitrogen) following the manufacturer's guidelines. RT-PCR experiments were performed and analysed as described in (Cowman et al., 2019). Primer sequences used were as follows: LIG4 Forward: TCCCGTTTTTGACTCCCTGG Reverse: GGCAAGCTCCGTTACCTCTG, ABL Forward: TGGGGCATGTCCTTTCCATC Reverse: GATGTCGGCAGTGACAGTGA, ERCC4 Forward: CTCCCTCGCCGTGTAACAAA Reverse: ACACCAAGATGCCAGTAATTAAATC, FEN1 Forward: GTTCCTGATTGCTGTTCGCC Reverse: ATGCGAATGGTGCGGTAGAA, MSH5 Forward: GTTTGCGAAGGTGTTGCGAA Reverse: GTCTGAGACCTCCTTGCCAC, PARP1 Forward: GCCCTAAAGGCTCAGAACGA Reverse: CTACTCGGTCCAAGATCGCC, UBE2T Forward: ATGTTAGCCACAGAGCCACC Reverse: ACCTAATATTTGAGCTCGCAGGT, WRN Forward: TCACGCTCATTGCTGTGGAT Reverse: CAACGATTGGAACCATTGGCA, PMS2 Forward: AGCACTGCGGTAAAGGAGTT Reverse: CAACCTGAGTTAGGTCGGCA, CYCLOA Forward: GCTTTGGGTCCAGGAATGG Reverse: GTTGTCCACAGTCAGCAATGGT. Cyclophillin A was used as a housekeeping gene. 
107 Identification of hypoxia response elements: The DNA sequence for LIG4 (NM_001352604.1) and

108

109

110

111

112

113

114

115

116

117

118

119

120

121

122

123

124

125

126

127

128

129

130

131

132

133

134

PMS2 (NM_000535.7) was obtained through the UCSC Genome Browser using human genome assembly h38 (Kent et al., 2002). The DNA sequence upstream of the first exon for each gene was examined for the consensus hypoxic response element, RCGTG, where R is A or G.

Western Blotting: Western blotting was performed as described in (Cowman et al., 2019). Briefly, 30-40 $\mu \mathrm{g}$ of protein were separated on $10 \%$ SDS-PAGE gels. Proteins were transferred onto nitrocellulose membrane $(0.2 \mu \mathrm{m})$, followed by primary and secondary antibody incubation. Signal was developed using Amersham ECL Prime Western blotting Detection reagent (GE Healthcare), and images taken using a G:BOX gel imaging system (Syngene UK).

Statistical Analyses: Student T-tests were performed using GraphPad Prism 6, for comparisons of means.

\section{Results}

HRR, NHEJ and MMR are strongly regulated by hypoxia in a range of hypoxic GBM cell lines To explore the global impact of tumour hypoxia on the expression of DNA repair genes in GBM cells, we used a NanoString assay. The NanoString nCounter gene expression system is a multiplexed assay, deemed more sensitive that RT-PCR and microarrays with less computationally heavy analysis than microarrays (Geiss et al., 2008). Four classical GBM cell lines (U87-MG, U251-MG, D566-MG and T98G), selected for their varied p53, MGMT status, and hypoxia sensitivity were cultured in three different oxygen tensions $\left(21 \%, 1 \%\right.$ and $\left.0.1 \% \mathrm{O}_{2}\right)$, and GLUT1 or VEGFA levels assessed by RT-PCR to confirm hypoxia had indeed resulted in hypoxia-induced gene expression changes (Fig S1). Our previous work determined that hypoxia does not impact cell death, doubling time, or cell proliferation of these cell lines (Richards et al., 2016). The DNA repair genes assessed by the NanoString assay, were pre-assigned to annotation groups representing cell signalling and DNA repair pathways. Directed global significance scores (DGS), which measure overall differential regulation and direction, were calculated for each cell line in $1 \%$ and $0.1 \% \mathrm{O}_{2}$ (Fig 1). Across all four cell lines, a number of pathways were downregulated,

Peer) reviewing PDF | (2020:10:54060:2:0:NEW 15 Mar 2021) 
135 including apoptosis, mismatch repair (MMR), non-homologous end-joining (NHEJ) and homologous 136 recombination repair (HRR) (Fig 1). MMR, NHEJ and HRR, are the core repair pathways involved in 137 repairing temozolomide and radiation-induced DNA damage in GBM (D'Atri et al., 1998; Cahill et al., 138 2007; Kondo et al., 2009; McFaline-Figueroa et al., 2015). Whilst previous reports show conflicted results 139 on hypoxia-induced changes to NHEJ, with both up and down-regulation of genes (Scanlon and Glazer, 140 2015), we here observed predominantly a downregulation of this pathway. In addition, the observed 141 downregulation of the HRR pathway in hypoxia is in line with previous findings, and the impact of hypoxia 142 on HRR efficiency has already been well characterised (Bindra et al., 2004, 2005; Meng et al., 2005;

143 Bindra and Glazer, 2007; Bindra, Crosby and Glazer, 2007; Chan et al., 2008).

144 Interestingly, increasing hypoxic severity from $1 \%$ to $0.1 \% \mathrm{O}_{2}$ drastically enhanced the regulation

145 of each annotation group, especially in D566-MG cells (Fig 1), and also increased the number of 146 significantly regulated genes in this cell line (Fig 2C). This correlates with the increase in GLUT1 mRNA 147 levels, a classical hypoxia marker, in $1 \%$ compared to $0.1 \% \mathrm{O}_{2}$ for D566-MG (Fig S1). Beyond the specific 148 D566-MG cells, more genes reached statistical significance at $0.1 \% \mathrm{O}_{2}$ in all cell lines, except for U251-

149 MG (Fig 2B), which had no dose-dependent response of VEGFA expression in hypoxia (Fig S1). In U87-

$150 M G, 20$ genes reached the strictest significance threshold of $p<0.001$ in $0.1 \% \mathrm{O}_{2}$ compared to 10 genes

151 in $1 \% \mathrm{O}_{2}$ (Fig 2A). In contrast, T98G displayed strong fold changes yet few genes reached statistical

152 significance (Fig 2D). To validate the NanoString results and determine the robustness of the data,

153 several gene candidates, which showed strong regulation in more than one cell line, were measured by

154 RT-PCR and showed good consistency (Fig S2). The NanoString assay therefore enabled us to

155 successfully assess the extent of DNA repair gene expression alteration in GBM cell lines exposed to 156 chronic hypoxia.

157

Essential components of NHEJ and MMR are downregulated by hypoxia

The mismatch repair pathway removes incorrectly inserted nucleotides added during DNA

160 replication, or removes modified bases generated by a DNA damaging agent. A sliding clamp composed 161 of MutSa (MSH2, MSH6) and MutLa (MLH1, PMS2) actively translocates along the DNA in search of 162 discontinuity (Gradia, Acharya and Fishel, 1997; Blackwell et al., 1999; Gradia et al., 1999; laccarino et 
163 al., 2000). EXO1 is responsible for nucleotide excision, and DNA polymerases replace excised 164 nucleotides (Longley, Pierce and Modrich, 1997; Zhang et al., 2005). The MMR pathway is essential for 165 effective temozolomide activity (D’Atri et al., 1998; Cahill et al., 2007; McFaline-Figueroa et al., 2015).

166 The expression of 13 components of MMR were assessed in the NanoString assay (Fig 3A, B). Whilst 167 MSH6, part of the MutSa complex, was unaffected by hypoxia, MSH2 was strongly downregulated 2.3168 fold in D566-MG and 2.0-fold in T98G incubated in $0.1 \% \mathrm{O}_{2}$ (Fig 3B), yet little change was observed at $1691 \% \mathrm{O}_{2}$. PMS2, a central component of the MutL $\alpha$ complex and a key player in temozolomide resistance 170 (D'Atri et al., 1998), was also downregulated in $1 \% \mathrm{O}_{2}$ and $0.1 \% \mathrm{O}_{2}$ for T98G $(0.1 \%=2.0$-fold), D566-MG $171(0.1 \%=2.6$-fold $)$ and U87-MG (0.1\% = 1.6-fold) (Fig 3A, B), and was additionally a top hit in D566-MG 172 (Fig 2C). However, there was no change to MLH1, the binding partner of PMS2, in line with previous 173 studies (Koshiji et al., 2005). Other changes include the downregulation of MSH5 in a number of cell lines 174 in $1 \% \mathrm{O}_{2}$ and $0.1 \% \mathrm{O}_{2}$, with particularly strong downregulation in D566-MG (4.1-fold) at $0.1 \% \mathrm{O}_{2}$ (Fig 3B). 175 MSH5 is primarily involved in meiosis (Bocker et al., 1999; Snowden et al., 2004), therefore the impact of 176 these hypoxia-induced changes in brain tumour cell lines is debatable. However, activation of meiotic 177 genes has been shown to aid in the initiation and maintenance of oncogenesis (McFarlane and 178 Wakeman, 2017), potentially underlying a new unknown role of the hypoxia-induced changes in MSH5. 179 NHEJ is a highly error-prone process, yet is the primary pathway for DSB repair. A DNA-PK and $180 \mathrm{Ku}$ (Ku70/Ku80) complex recognises the DSB (Gottlieb and Jackson, 1993; Kurimasa et al., 1999). The 181 ends of DNA are processed by various enzymes including Artemis, PNK, WRN and DNA polymerases 182 (Mahaney, Meek and Lees-Miller, 2009), followed by re-joining by DNA Ligase IV complexed with 183 XRCC4. Little consensus has been achieved as to the impact of hypoxia on NHEJ. Components of the 184 damage recognition complex (Ku70 - XRCC6, Ku80 - XRCC5, DNA-PK - PRKDC) remain largely 185 unaffected by hypoxia. However, in all cell lines tested, LIG4 (DNA Ligase IV) was downregulated at least 1861.5 -fold in hypoxia $\left(1 \%\right.$ and $0.1 \% \mathrm{O}_{2}$.), although, this was only statistically significant in U87-MG (Fig 3C, 187 D). Interestingly, the extent of downregulation appears to strengthen with increasing hypoxia severity. In 188 contrast, the expression level of XRCC4, the binding partner of DNA Ligase IV, was not impacted by 189 hypoxia (Fig 3C, D). Although, XRCC4 and DNA Ligase IV are both essential for effective NHEJ, there is 190 no evidence to suggest their transcription is co-regulated. Therefore, it is feasible that hypoxia can impact 
191 the expression of each gene in different ways. Work by Meng et al 2005, observed similar hypoxia-

192 induced gene expression changes for LIG4, with no change in XRCC4 (Meng et al., 2005).

193 Overall, gene expression for components of both MMR and NHEJ were significantly impacted by

194 hypoxia. Primarily, downregulation was observed, which could lead to reduced functionality of the repair

195 pathways if the accessible pool of DNA repair proteins has been depleted. PMS2 and LIG4, essential

196 components of their respective repair pathways, are involved in chemoresistance (D'Atri et al., 1998;

197 Adachi et al., 2002; Kondo et al., 2010), and were downregulated in at least two cell lines in both $1 \%$ and

$1980.1 \% \mathrm{O}_{2}$. Therefore, the mechanisms of regulation of these two genes was further examined.

199

200 Chronic and acute hypoxic exposure leads to PMS2 and LIG4 downregulation.

201 Despite the fact that hypoxic exposure in tumours is long-term, alterations to DNA repair gene

202 expression by hypoxia are commonly explored upon acute hypoxic exposure. To determine the duration

203 of hypoxia necessary to trigger downregulation of $P M S 2$ and $L / G 4$, their level of expression in $1 \% \mathrm{O}_{2}$ was

204 assessed over-time in D566-MG cells, the cell line in which the strongest regulation for these target

205 genes was observed (Fig 4A). Both PMS2 and LIG4 were downregulated after only one day of hypoxic

206 exposure and remained downregulated over the 5-day period (Fig 4A). Besides the transcriptional

207 regulation, PMS2 protein levels were also downregulated by chronic hypoxia in D566-MG, and U87-MG

208 (Fig 4B), suggesting that the gene expression changes translate to the protein level. LIG4 protein levels

209 could not be measured due to the lack of availability of a good quality antibody.

210 Previous studies demonstrated the involvement of HIF in the alteration of DNA repair gene

211 expression. For example, downregulation of NBN, a component of HRR, arises due to the displacement

212 of MYC by HIF at the NBN promoter (To et al., 2006). Examination of DNA sequence upstream of the

213 initiating codon revealed that both PMS2 and LIG4 contained the consensus core hypoxia response

214 element sequence RCGTG, where R is G or A. This suggests that HIF may be responsible for the

215 hypoxia-induced regulation of PMS2 and LIG4. The HIF pathway forms a negative feedback loop with the

216 prolyl hydroxylase domain-containing protein 2 (PHD2) (Stiehl et al., 2006; Bagnall et al., 2014), resulting

217 in a transient accumulation of HIF and lower levels after extended periods of hypoxia, typically after $12 \mathrm{~h}$.

218 However, in D566-MG and U87-MG cells, after 5 days of hypoxic exposure, HIF-1a remained high, with

Peer) reviewing PDF | (2020:10:54060:2:0:NEW 15 Mar 2021) 
219 similar levels at $6 \mathrm{~h}$ and $24 \mathrm{~h}$, and HIF-2 $\alpha$ remained relatively consistent through the time course (Fig 5A).

220 To test the involvement of HIF in the expression levels of LIG4 and PMS2, we initially aimed to use a

221 silencing strategy. However, both D566-MG and U87-MG were highly sensitive to siRNA transfection

222 performed to knockdown HIF, therefore a pharmacological approach was adopted. Acriflavin can inhibit

223 HIF-1 and HIF-2 through binding to the PAS-B subdomain in the $\alpha$ subunit, preventing dimerisation of the

$224 \alpha$ and $\beta$ subunits, and reducing HIFs transcriptional activity (Lee et al., 2009). Treatment with acriflavin

225 was sufficient to reduce hypoxia-induced GLUT1 expression, a typical HIF target gene (Fig S3A). In both

226 D566-MG and U87-MG cell lines, acriflavin opposed hypoxia-induced LIG4 mRNA regulation, although

227 this was not statistically significant (Fig 5B). In contrast, the level of PMS2 was not altered by acriflavin

228 treatment (Fig S3B), suggesting different mechanisms of regulation for both genes, and that HIF is not the

229 only player in hypoxia-induced regulation of DNA repair genes.

230

\section{Discussion}

232

Tumour hypoxia plays an essential role in tumour progression, metastasis and drug resistance,

233 leading to poor patient outcome, particularly for GBM patients. Hypoxia has been shown to impact

234 numerous signalling pathways including the cell cycle, metabolism and apoptosis, yet additionally,

235 hypoxia can have a significant impact on DNA repair mechanisms. We have shown here that several key

236 DNA repair pathways were downregulated by hypoxia, including MMR and NHEJ, both essential

237 pathways for the repair of modified/mismatch bases and double strand breaks respectively. Further

238 analysis determined that PMS2 (MMR) and LIG4 (NHEJ), essential components of their respective

239 pathways, were downregulated across multiple cell lines after chronic and acute hypoxic exposure,

240 providing potential targets for re-sensitisation of hypoxic tumour cells to DNA damaging therapies.

241

\section{Mismatch repair an essential repair pathway for temozolomide efficacy}

243 We observed hypoxia-induced downregulation of PMS2 (Figure 3A, B), a vital component of MMR,

244 involved in the search for discontinuity in DNA. MMR is required for repair of mismatched bases resulting

245 from replication errors or DNA damaging agents. Defects in any of the critical MMR repair proteins

246 (PMS2, MLH1, MSH2, MSH6), can lead to hypermutation and microsatellite instability, due to the

Peer) reviewing PDF | (2020:10:54060:2:0:NEW 15 Mar 2021) 
247 increased number of point mutations (Kim et al., 1999). These point mutations drive tumorigenesis and 248 cancer progression, which will directly contribute to poor patient outcome. In multicellular brain tumour 249 spheroids, downregulation of PMS2 and MLH1 promoted the initiation of tumour cell formation and growth 250 (Collins et al., 2011). In addition, in 1996, the link between MMR and cisplatin resistance was established, 251 when cisplatin-resistant human ovarian adenocarcinoma cells were found to have reduced MLH1 protein 252 (Aebi et al., 1996). In the same year, the downregulation of both MLH1 and MLH2 was found to induce 253 cisplatin and carboplatin resistance (Fink, Aebi and Howell, 1998), although this was only a low-level 254 resistance. We see little change in the gene expression of $M L H 1$ and $M L H 2$, however, previously, we 255 have reported that indeed, hypoxia causes low-level resistance to cisplatin in GBM cells (Cowman et al., 256 2019), which could be due to PMS2 downregulation. MMR contribution to cisplatin toxicity has been well 257 described, yet other DNA repair pathways may also play a role (Pani et al., 2007). More importantly for 258 GBM, MMR is essential for temozolomide-induced apoptosis. The O6-methylguanine lesions 259 inappropriately paired with thymine, are recognised and repaired by MMR. This results in thymine 260 excision creating a long gap in the DNA which is filled and sealed. However, during this process thymine 261 is matched again with the O6-methylguanine resulting in a futile repair cycle. This leads to the formation 262 of a double-strand breaks during replication, which triggers cell death via apoptosis (Klapacz., et al 2009.; 263 Karran and Bignami, 1994; Kaina and Christmann, 2019; D'Atri et al., 1998). Thus, MMR is required for 264 TMZ efficacy. Conversely, loss of double-strand break repair systems such as homologous recombination 265 repair can enhance TMZ effectiveness as these newly formed breaks go unrepaired. Loss of the MMR component, MSH6, has been associated with increased tumour progression during temozolomide treatment in GBM (Cahill et al., 2007), and alterations of $M S H 2$ expression can predict patient response

268 to temozolomide therapy, with reduced expression correlating with decreased overall patient survival 269 (McFaline-Figueroa et al., 2015). Downregulation of PMS2 in hypoxia could have a significant clinical impact for GBM by contributing to increased mutation rate driving tumorigenesis and reduced sensitivity

271 to temozolomide.

272

273 DNA Ligase IV is crucial for NHEJ fidelity 
NHEJ is essential for effective induction of apoptosis by temozolomide treatment (Kondo et al.,

275 2009). Among the key components of NHEJ, we observed a significant hypoxia-induced downregulation

276 of LIG4 in multiple GBM cell lines, in line with previous observations (Meng et al., 2005). DNA Ligase IV is

277 essential for re-joining broken DNA ends, yet is also required to prevent degradation of the ends of DNA,

278 thus promoting accurate re-joining (Smith et al., 2003). Cell lines with hypermorphic mutations in LIG4,

279 resulting in residual DNA Ligase IV function, are able to perform end-joining yet with reduced fidelity. In

280 mice, loss of a single allele of LIG4 results in the formation of soft tissue sarcomas, as a result of

281 increased genomic instability (Sharpless et al., 2001). Therefore, downregulation of LIG4 may reduce the

282 effectiveness of NHEJ, thereby promoting genomic instability and further fuel tumorigenesis. However, in

283 contrast, LIG4 deficient cell lines have been shown to be more sensitive to ionising radiation (Adachi et

284 al., 2002). Additionally, work by Kondo et al found that LIG4 deficient cells were also more sensitive to

285 temozolomide and Nimustine (ACNU), and siRNA of LIG4 enhanced cell lethality of both

286 chemotherapeutics (Kondo et al., 2009, 2010). Although an increased genetic instability potentially arising

287 due to LIG4 downregulation may drive development and progression of GBM, the potential positive

288 impact of increased temozolomide sensitivity may outweigh this negative implication. This highlights the

289 double-edged sword of hypoxia, where both pro- and anti-cancer adaptations arise, which can be

290 complex and difficult to untangle. Discovery of targeted therapies, which can exploit the anti-cancer

291 components of tumour hypoxia would be advantageous, yet for this to occur further understanding of the

292 molecular mechanism of hypoxia-induced changes needs to be gained.

293

294 The role of HIF in hypoxia-induced DNA repair gene regulation

295 Long term hypoxia-induced changes in DNA repair gene expression can be orchestrated by a

296 range of mechanisms, including epigenetic modifications. For example, alterations to histone methylation

297 and acetylation at the promoters of BRCA1 and RAD51 leads to reduced gene expression (Lu et al.,

298 2011). However, short-term transient changes to DNA repair gene expression are more commonly

299 studied, with mechanisms both dependent and independent of HIF being described. Using an inhibitor of

$300 \mathrm{HIF}$, we showed that HIF is involved in the downregulation of LIG4 but not PMS2 in hypoxic GBM cells

301 (Figure 5B). HIF can directly modulate the transcription of genes through binding at the hypoxic response 
302 elements within promoters of DNA repair genes. However, the presence of hypoxic response elements 303 does not guarantee direct HIF regulation. For example, in the MLH1 promoter, hypoxia response

304 elements have been identified (Mihaylova et al., 2003) suggesting direct HIF regulation, yet a mechanism 305 of MLH1 downregulation independent of HIF have also been discovered (Mihaylova et al., 2003; Koshiji et 306 al., 2005; Rodríguez-Jiménez et al., 2008).

307 On the other hand, other genes are altered in a HIF-independent way, such as for example, via 308 the E2F transcription factor binding in hypoxia. Indeed, in normoxia, the expression of BRCA1 is 309 mediated through the binding of the activating factor E2F1 as well as the E2F4/P130 suppressor.

310 However, under hypoxic conditions, p130 binding to E2F4 is enhanced, due to alterations to p130 post-

311 translational modifications. This results in an increase in E2F4/p130 transcriptional suppressor binding at

312 the BRAC1 promoter, reducing the rate of transcription (Bindra et al., 2005). Regulation of RAD51 and

313 FANCD2 is thought to also occur by an E2F related mechanism (Bindra and Glazer, 2007; Scanlon and

314 Glazer, 2014). The regulation of PMS2 may be through a similar mechanism.

315

\section{Conclusions}

317 We have shown that chronic hypoxia results in the downregulation of multiple DNA repair 318 pathways in GBM including essential components of MMR and NHEJ pathways. These alterations will 319 likely not only impact chemotherapeutic treatment efficiency but also enhance the tumour genomic 320 instability, hence further fuelling its development. The development of HIF inhibitors for cancer treatment

321 is currently a popular area of research (reviewed in Fallah and Rini, 2019), and will undoubtedly be of 322 great benefit for reducing the undesirable pro-tumorigenic impact of hypoxia. However, HIF is not the sole 323 regulator of the hypoxia-induced reprogramming of the transcriptional landscape of DNA repair, as we 324 have shown here with PMS2 regulation. Whether HIF inhibition could be sufficient to re-sensitise hypoxic brain tumour cells to radio- and chemotherapy will require further investigation. 
References

327

328

329

330

331

332

333

334

335

336

337

338

339

340

341

342

343

344

345

346

347

348

349

350

351

352

353

354

355

356

357

Adachi N, Ishino T, Ishii Y, Takeda S, Koyama H. 2002. DNA ligase IV-deficient cells are more resistant to ionizing radiation in the absence of Ku70: Implications for DNA double-strand break repair. Proceedings of the National Academy of Sciences 98:12109-12113. DOI: 10.1073/pnas.201271098.

Aebi S, Kurdi-haidar B, Gordon R, Cenni B, Zheng H, Fink D, Christen RD, Boland CR, Koi M, Fishel R, Howell SB. 1996. Loss of DNA Mismatch Repair in Acquired Resistance to Cisplatin Loss of DNA Mismatch Repair in Acquired Resistance to Cisplatin. Cancer Research 2:3087-3090.

Athanassiou H, Synodinou M, Maragoudakis E, Paraskevaidis M, Verigos C, Misailidou D, Antonadou D, Saris G, Beroukas K, Karageorgis P. 2005. Randomized phase II study of temozolomide and radiotherapy compared with radiotherapy alone in newly diagnosed glioblastoma multiforme. Journal of Clinical Oncology 23:2372-2377. DOI: 10.1200/JCO.2005.00.331.

Bagnall J, Leedale J, Taylor SE, Spiller DG, White MRH, Sharkey KJ, Bearon RN, Sée V. 2014. Tight control of hypoxia-inducible factor- $\alpha$ transient dynamics is essential for cell survival in hypoxia. Journal of Biological Chemistry 289:5549-5564. DOI: 10.1074/jbc.M113.500405.

Banin S, Moyal L, Shieh S-Y, Taya Y, Anderson CW, Chessa L, Smorodinsky NI, Prives C, Reiss Y, Shiloh Y, Ziv Y. 1998. Enhanced Phosphorytation of p53 by ATM in Response to DNA Damage. Science 281:1674-1677. DOI: 10.1126/science.281.5383.1674.

Bindra RS, Crosby ME, Glazer PM. 2007. Regulation of DNA repair in hypoxic cancer cells. Cancer and Metastasis Reviews 26:249-260. DOI: 10.1007/s10555-007-9061-3.

Bindra RS, Glazer PM. 2007. Repression of RAD51 gene expression by E2F4/p130 complexes in hypoxia. Oncogene 26:2048-2057. DOI: 10.1038/sj.onc.1210001.

Blackwell LJ, Martik D, Bjornson KP, Bjornson ES, Modrich P. 1999. Nucleotide-promoted release of hMutSa from heteroduplex DNA is consistent with an ATP-dependent translocation mechanism. Journal of Biological Chemistry 273:32055-32062. DOI: 10.1074/jbc.273.48.32055.

Bocker T, Barusevicius A, Snowden T, Rasio D, Guerrette S, Robbins D, Schmidt C, Burczak J, Croce CM, Copeland T, Kovatich AJ, Fishel R. 1999. hMSH5: A human MutS homologue that forms a novel heterodimer with hMSH4 and is expressed during spermatogenesis. Cancer Research 59:816-822.

Brada M, Judson I, Beale P, Moore S, Reidenberg P, Statkevich P, Dugan M, Batra V, Cutler D. 1999. Phase I dose-escalation and pharmacokinetic study of temozolomide (SCH 52365) for refractory or relapsing malignancies. British Journal of Cancer 81:1022-30. DOI: 10.1038/sj.bjc.6690802. 
359

360

361

362

363

364

365

366

367

368

369

370

371

372

373

374

375

376

377

378

379

380

381

382

383

384

385

386

387

388

389

390

391

392

393

394
MR, Curry WT, Lafrate AJ, Louis DN. 2007. Loss of the mismatch repair protein MSH6 in human glioblastomas is associated with tumor progression during temozolomide treatment. Clinical Cancer Research 13:2038-2045. DOI: 10.1158/1078-0432.CCR-06-2149.

Canman CE, Lim DS, Cimprich KA, Taya Y, Tamai K, Sakaguchi K, Appella E, Kastan MB, Siliciano JD. 1998. Activation of the ATM kinase by ionizing radiation and phosphorylation of p53. Science 281:1677-1679. DOI: 10.1126/science.281.5383.1677.

Chang CH, Horton J, Schoenfeld D, Salazer O, Perez-Tamayo R, Kramer S, Weinstein a, Nelson JS, Tsukada Y. 1983. Comparison of postoperative radiotherapy and combined postoperative radiotherapy and chemotherapy in the multidisciplinary management of malignant gliomas. A joint Radiation Therapy Oncology Group and Eastern Cooperative Oncology Group study. Cancer 52:997-1007. DOI: 10.1002/1097-0142(19830915)52:6<997::AID-CNCR2820520612>3.0.CO;2-2.

Cheng CL, Johnson SP, Keir ST, Quinn J a, Ali-Osman F, Szabo C, Li H, Salzman AL, Dolan ME, Modrich P, Bigner DD, Friedman HS. 2005. Poly(ADP-ribose) polymerase-1 inhibition reverses temozolomide resistance in a DNA mismatch repair-deficient malignant glioma xenograft. Molecular Cancer Therapeutics 4:1364-1368. DOI: 10.1158/1535-7163.MCT-05-0128.

Collins SL, Hervé R, Keevil CW, Blaydes JP, Webb JS. 2011. Down-regulation of DNA mismatch repair enhances initiation and growth of neuroblastoma and brain tumour multicellular spheroids. PLOS ONE 6:1-8. DOI: 10.1371/journal.pone.0028123.

Cowman S, Fan YN, Pizer B, Sée V. 2017. Decrease of Nibrin expression in chronic hypoxia is associated with hypoxia-induced chemoresistance in medulloblastoma cells. bioRxiv. DOI: $10.1101 / 227207$.

D'Atri S, Tentori L, Lacal PM, Graziani G, Pagani E, Benincasa E, Zambruno G, Bonmassar E, Jiricny J. 1998. Involvement of the mismatch repair system in temozolomide-induced apoptosis. Molecular Pharmacology 54:334-341. DOI: 10.1124/mol.54.2.334.

Dolecek TA, Propp JM, Stroup NE, Kruchko C. 2012. CBTRUS statistical report: Primary brain and central nervous system tumors diagnosed in the United States in 2005-2009. Neuro-Oncology 14:v1-v88. DOI: 10.1093/neuonc/nos218.

Dudás J, Schartinger VH, Romani A, Schweigl G, Kordsmeyer K, Marta PI, Url C, Kral F, Riechelmann H. 2014. Cell cycle association and hypoxia regulation of excision repair cross complementation group 1 protein (ERCC1) in tumor cells of head and neck cancer. Tumor Biology 35:7807-7819. DOI: $10.1007 / \mathrm{s} 13277-014-2001-2$.

Epstein ACR, Gleadle JM, Mcneill LA, Hewitson KS, Rourke JO, Mole DR, Mukherji M, Metzen E, Wilson MI, Dhanda A, Tian Y, Masson N, Hamilton DL, Jaakkola P, Barstead R, Hodgkin J, Maxwell PH, Pugh CW, Schofield CJ, Ratcliffe PJ. 2001. C. elegans EGL-9 and mammalian homologs define a family of dioxygenases that regulate HIF by prolyl hydroxylation. Cell 107:43-54. DOI: 10.1016/S0092-8674(01)00507-4.

Peer] reviewing PDF | (2020:10:54060:2:0:NEW 15 Mar 2021) 
395

396

397

398

399

400

401

402

403

404

405

406

407

408

409

410

411

412

413

414

415

416

417

418

419

420

421

422

423

424

425

426

Esteller M, Garcia-Foncillas J, Andion E. 2000. Inactivation of The DNA Repair Gene MGMT And The Clinical Response of Gliomas to Alkylating Agents. New England Journal of Medicine 343:4-8.

Fallah J, Rini BI. 2019. HIF Inhibitors: Status of Current Clinical Development. Current Oncology Reports 21:6. DOI: 10.1007/s11912-019-0752-z.

Fink D, Aebi S, Howell SB. 1998. The role of DNA mismatch repair in drug resistance. Clinical Cancer Research 4:1-6.

Ge X, Pan MH, Wang L, Li W, Jiang C, He J, Abouzid K, Liu LZ, Shi Z, Jiang BH. 2018. Hypoxiamediated mitochondria apoptosis inhibition induces temozolomide treatment resistance through miR-26a/Bad/Bax axis. Cell Death and Disease 9. DOI: 10.1038/s41419-018-1176-7.

Geiss GK, Bumgarner RE, Birditt B, Dahl T, Dowidar N, Dunaway DL, Fell HP, Ferree S, George RD, Grogan T, James JJ, Maysuria M, Mitton JD, Oliveri P, Osborn JL, Peng T, Ratcliffe AL, Webster PJ, Davidson EH, Hood L. 2008. Direct multiplexed measurement of gene expression with colorcoded probe pairs. Nature Biotechnology 26:317-325. DOI: 10.1038/nbt1385.

Glassner BJ, Weeda G, Allan JM, Broekhof JLM, Carls NHE, Donker I, Engelward BP, Hampson RJ, Hersmus R, Hickman MJ, Roth RB, Warren HB, Wu MM, Hoeijmakers JHJ, Samson LD. 1999. DNA repair methyltransferase (Mgmt) knockout mice are sensitive to the lethal effects of chemotherapeutic alkylating agents. Mutagenesis 14:339-347. DOI: 10.1093/mutage/14.3.339.

Gottlieb TM, Jackson P. 1993. The DNA-Dependent Protein Kinase: Requirement for DNA ends and Association with Ku Antigen. Cell 72:131-142. DOI: 10.1016/0092-8674(93)90057-W.

Gradia S, Acharya S, Fishel R. 1997. The human mismatch recognition complex hMSH2-hMSH6 functions as a novel molecular switch. Cell 91:995-1005. DOI: 10.1016/S0092-8674(00)80490-0.

Gradia S, Subramanian D, Wilson T, Acharya S, Makhov A, Griffith J, Fishel R. 1999. hMSH2-hMSH6 forms a hydrolysis-independent sliding clamp on mismatched DNA. Molecular Cell 3:255-261. DOI: 10.1016/S1097-2765(00)80316-0.

Hegi., Marie-france, Tribolet N De, Weller M, Kros JM, Hainfellner JA, Mason W, Mariani L, Bromberg JEC, Hau P, Stupp R. 2005. Gene Silencing and Benefit from Temozolomide in Glioblastoma. New England Journal of Medicine 352:997-1003.

laccarino I, Marra G, Dufner P, Jiricny J. 2000. Mutation in the magnesium binding site of hMSH6 disables the hMutSa sliding clamp from translocating along DNA. Journal of Biological Chemistry 275:2080-2086. DOI: 10.1074/jbc.275.3.2080.

Kaina B, Christmann M. 2019. DNA repair in personalized brain cancer therapy with temozolomide and nitrosoureas. DNA Repair 78:128-141. DOI: 10.1016/j.dnarep.2019.04.007. 
427

428

429

430

431

432

433

434

435

436

437

438

439

440

441

442

443

444

445

446

447

448

449

450

451

452

453

454

455

456

457

458

459

460

461

462

463

Karran P, Bignami M. 1994. DNA damage tolerance, mismatch repair and genome instability. BioEssays 16:833-839. DOI: 10.1002/bies.950161110.

Kent WJ, Sugnet CW, Furey TS, Roskin KM, Pringle TH, Zahler AM, Haussler a. D. 2002. The Human Genome Browser at UCSC. Genome Research 12:996-1006. DOI: 10.1101/gr.229102.

Kim N, Bozek G, Lo JC, Storb U. 1999. Different mismatch repair deficiencies all have the same effects on somatic hypermutation: intact primary mechanism accompanied by secondary modifications. Journal of Experimental Medicine 190:21-30. DOI: 10.1084/jem.190.1.21.

Klapacz J, Meira LB, Luchetti DG, Calvo JA, Bronson RT, Edelmann W, Samson LD. 2009. O6methylguanine-induced cell death involves exonuclease 1 as well as DNA mismatch recognition in vivo. Proceedings of the National Academy of Sciences of the United States of America 106:576581. DOI: $10.1073 /$ pnas.0811991106.

Kondo N, Takahashi A, Mori E, Noda T, Su X, Ohnishi K, McKinnon PJ, Sakaki T, Nakase H, Ono K, Ohnishi T. 2010. DNA ligase IV is a potential molecular target in ACNU sensitivity. Cancer Science 101:1881-1885. DOI: 10.1111/j.1349-7006.2010.01591.x.

Kondo N, Takahashi A, Mori E, Ohnishi K, McKinnon PJ, Sakaki T, Nakase H, Ohnishi T. 2009. DNA ligase IV as a new molecular target for temozolomide. Biochemical and Biophysical Research Communications 387:656-660. DOI: 10.1016/j.bbrc.2009.07.045.

Koshiji M, To KKW, Hammer S, Kumamoto K, Harris AL, Modrich P, Huang LE. 2005. HIF-1a induces genetic instability by transcriptionally downregulating MutSa expression. Molecular Cell 17:793-803. DOI: 10.1016/j.molcel.2005.02.015.

Kurimasa A, Kumano S, Boubnov N V, Story MD, Tung CS, Peterson SR, Chen DJ. 1999. Requirement for the kinase activity of human DNA-dependent protein kinase catalytic subunit in DNA strand break rejoining. Molecular and Cellular Biology 19:3877-84. DOI: 10.1128/MCB.19.5.3877.

Lee K, Zhang H, Qian DZ, Rey S, Liu JO, Semenza GL. 2009. Acriflavine inhibits HIF-1 dimerization, tumor growth, and vascularization. Proceedings of the National Academy of Sciences 106:17910 17915. DOI: $10.1073 /$ pnas.0909353106.

Liau LM, Ashkan K, Tran DD, Campian JL, Trusheim JE, Cobbs CS, Heth JA, Salacz M, Taylor S, D'Andre SD, Iwamoto FM, Dropcho EJ, Moshel YA, Walter KA, Pillainayagam CP, Aiken R, Chaudhary R, Goldlust SA, Bota DA, Duic P, Grewal J, Elinzano H, Toms SA, Lillehei KO, Mikkelsen T, Walpert T, Abram SR, Brenner AJ, Brem S, Ewend MG, Khagi S, Portnow J, Kim LJ, Loudon WG, Thompson RC, Avigan DE, Fink KL, Geoffroy FJ, Lindhorst S, Lutzky J, Sloan AE, Schackert G, Krex D, Meisel HJ, Wu J, Davis RP, Duma C, Etame AB, Mathieu D, Kesari S, Piccioni D, Westphal M, Baskin DS, New PZ, Lacroix M, May SA, Pluard TJ, Tse V, Green RM, Villano JL, Pearlman M, Petrecca K, Schulder M, Taylor LP, Maida AE, Prins RM, Cloughesy TF, Mulholland P, Bosch ML. 2018. First results on survival from a large Phase 3 clinical trial of an autologous dendritic cell vaccine in newly diagnosed glioblastoma. Journal of Translational Medicine 16:1-9. DOI: 10.1186/s12967-018-1507-6. 
464

465

466

467

468

469

470

471

472

473

474

475

476

477

478

479

480

481

482

483

484

485

486

487

488

489

490

491

492

493

494

495

496

Longley MJ, Pierce AJ, Modrich P. 1997. DNA polymerase $\delta$ is required for human mismatch repair in vitro. Journal of Biological Chemistry 272:10917-10921. DOI: 10.1074/jbc.272.16.10917.

Lu Y, Chu A, Turker MS, Glazer PM. 2011. Hypoxia-Induced Epigenetic Regulation and Silencing of the BRCA1 Promoter. Molecular and Cellular Biology 31:3339-3350. DOI: 10.1128/MCB.01121-10.

Mahaney BL, Meek K, Lees-Miller SP. 2009. Repair of ionizing radiation-induced DNA double-strand breaks by non-homologous end-joining. Biochemical Journal 417:639-650. DOI: 10.1042/BJ20080413.

Marampon F, Gravina GL, Zani BM, Popov VM, Fratticci A, Cerasani M, Di Genova D, Mancini M, Ciccarelli C, Ficorella C, Di Cesare E, Festuccia C. 2014. Hypoxia sustains glioblastoma radioresistance through ERKs/DNA-PKcs/HIF-1a functional interplay. International Journal of Oncology 45:2121-2131. DOI: 10.3892/ijo.2014.2358.

McFaline-Figueroa JL, Braun CJ, Stanciu M, Nagel ZD, Mazzucato P, Sangaraju D, Cerniauskas E, Barford K, Vargas A, Chen Y, Tretyakova N, Lees JA, Hemann MT, White FM, Samson LD. 2015. Minor changes in expression of the mismatch repair protein MSH2 exert a major impact on glioblastoma response to temozolomide. Cancer Research 75:3127-3138. DOI: 10.1158/00085472.CAN-14-3616.

McFarlane RJ, Wakeman JA. 2017. Meiosis-like functions in oncogenesis: A new view of cancer. Cancer Research 77:5712-5716. DOI: 10.1158/0008-5472.CAN-17-1535.

Meng AX, Jalali F, Cuddihy A, Chan N, Bindra RS, Glazer PM, Bristow RG. 2005. Hypoxia downregulates DNA double strand break repair gene expression in prostate cancer cells. Radiotherapy and Oncology 76:168-176. DOI: 10.1016/j.radonc.2005.06.025.

Mihaylova VT, Bindra RS, Yuan J, Campisi D, Narayanan L, Jensen R, Giordano F, Johnson RS, Rockwell S, Glazer PM. 2003. Decreased Expression of the DNA Mismatch Repair Gene Mlh1 under Hypoxic Stress in Mammalian Cells. Molecular and Cellular Biology 23:3265-3273. DOI: 10.1128/MCB.23.9.3265.

Omuro A, DeAngelis LM. 2013. Glioblastoma and Other Malignant Gliomas. Jama 310:1842. DOI: 10.1001/jama.2013.280319.

Pani E, Stojic L, El-Shemerly M, Jiricny J, Ferrari S. 2007. Mismatch repair status and the response of human cells to cisplatin. Cell Cycle 6:1796-1802. DOI: 10.4161/cc.6.14.4472.

Rampling R, Cruickshank G, Lewis AD, Fitzsimmons SA, Workman P. 1994. Direct measurement of pO2 distribution and bioreductive enzymes in human malignant brain tumors. International Journal of Radiation Oncology*Biology*Physics 29:427-431. DOI: 10.1016/0360-3016(94)90432-4.

Richards R, Jenkinson MD, Haylock BJ, See V. 2016. Cell cycle progression in glioblastoma cells is

Peer) reviewing PDF | (2020:10:54060:2:0:NEW 15 Mar 2021) 
unaffected by pathophysiological levels of hypoxia. PeerJ 4:e1755. DOI: 10.7717/peerj.1755.

498

499

500

501

502

503

504

505

506

507

508

509

510

511

512

513

514

515

516

517

518

519

520

521

522

523

524

525

526

527

528

Rodríguez-Jiménez FJ, Moreno-Manzano V, Lucas-Dominguez R, Sánchez-Puelles J-M. 2008. Hypoxia Causes Downregulation of Mismatch Repair System and Genomic Instability in Stem Cells. Stem Cells 26:2052-2062. DOI: 10.1634/stemcells.2007-1016.

Saito SNI, Goodarzi AA, Higashimoto Y, Noda Y, Lees-Miller SP, Appella E, Anderson CW. 2002. ATM mediates phosphorylation at multiple p53 sites, including Ser46, in response to ionizing radiation. Journal of Biological Chemistry 277:12491-12494. DOI: 10.1074/jbc.C200093200.

Scanlon SE, Glazer PM. 2014. Hypoxic Stress Facilitates Acute Activation and Chronic Downregulation of Fanconi Anemia Proteins. Molecular Cancer Research 12:1016-1028. DOI: 10.1158/15417786.MCR-13-0628.

Scanlon SE, Glazer PM. 2015. Multifaceted control of DNA repair pathways by the hypoxic tumor microenvironment. DNA Repair 32:180-189. DOI: 10.1016/j.dnarep.2015.04.030.

Sharpless NE, Ferguson DO, O'hagan RC, Castrillon DH, Lee C, Farazi PA, Alson S, Fleming J, Morton CC, Frank K, Chin L, Alt FW, DePinho RA. 2001. Impaired nonhomologous end-joining provokes soft tissue sarcomas harboring chromosomal translocations, amplifications, and deletions. Molecular Cell 8:1187-1196. DOI: 10.1016/S1097-2765(01)00425-7.

Smith J, Riballo E, Kysela B, Baldeyron C, Manolis K, Masson C, Lieber MR, Papadopoulo D, Jeggo P. 2003. Impact of DNA ligase IV on the fidelity of end joining in human cells. Nucleic Acids Research 31:2157-2167. DOI: 10.1093/nar/gkg317.

Snowden T, Acharya S, Butz C, Berardini M, Fishel R. 2004. hMSH4-hMSH5 recognizes holliday junctions and forms a meiosis-specific sliding clamp that embraces homologous chromosomes. Molecular Cell 15:437-451. DOI: 10.1016/j.molcel.2004.06.040.

Stiehl DP, Wirthner R, Köditz J, Spielmann P, Camenisch G, Wenger RH. 2006. Increased prolyl 4hydroxylase domain proteins compensate for decreased oxygen levels: Evidence for an autoregulatory oxygen-sensing system. Journal of Biological Chemistry 281:23482-23491. DOI: 10.1074/jbc.M601719200.

To KK-W, Sedelnikova O a, Samons M, Bonner WM, Huang LE. 2006. The phosphorylation status of PAS-B distinguishes HIF-1alpha from HIF-2alpha in NBS1 repression. The EMBO Journal 25:478494. DOI: 10.1038/sj.emboj.7601369.

Turenne GA, Paul P, Laflair L, Price BD. 2001. Activation of p53 transcriptional activity requires ATM's kinase domain and multiple $\mathrm{N}$-terminal serine residues of p53. Oncogene 20:5100-5110. DOI: 10.1038/sj.onc.1204665.

529 Vaupel P, Harrison L. 2004. Tumor hypoxia: causative factors, compensatory mechanisms, and cellular 

response. The Oncologist 9:4-9.

531

532

533

534

535

536

537

538
Zhang Z, Tang L, Zhan R, Tong Y, Yao H, Du L. 2004. Immunotherapy of intracranial G422 glioblastoma with dendritic cells pulsed with tumor extract or RNA. J Zhejiang Univ Sci 5:1298-1303. DOI: 10.1631/jzus.2004.1298.

Zhang Y, Yuan F, Presnell SR, Tian K, Gao Y, Tomkinson AE, Gu L, Li GM. 2005. Reconstitution of 5'directed human mismatch repair in a purified system. Cell 122:693-705. DOI: 10.1016/j.cell.2005.06.027. 


\section{Figure 1}

Apoptosis, NHEJ, HRR and MMR are downregulated in multiple hypoxic GBM cell lines.

(A) U87-MG, (B) U251-MG, (C) D566-MG and (D) T98G cells were incubated in $21 \%, 1 \%$ or

$0.1 \% \mathrm{O}_{2}$ for 5 days before gene expression analysis. Directed global significance scores were calculated for each defined annotation group and cell line, in $1 \%$ and $0.1 \% \mathrm{O}_{2}$, using the NanoString nSolver Advanced Analysis Software (see methods). Scores are represented in a heat map, where red and blue represent up and downregulation respectively. Data is representative of three independent experiments. 


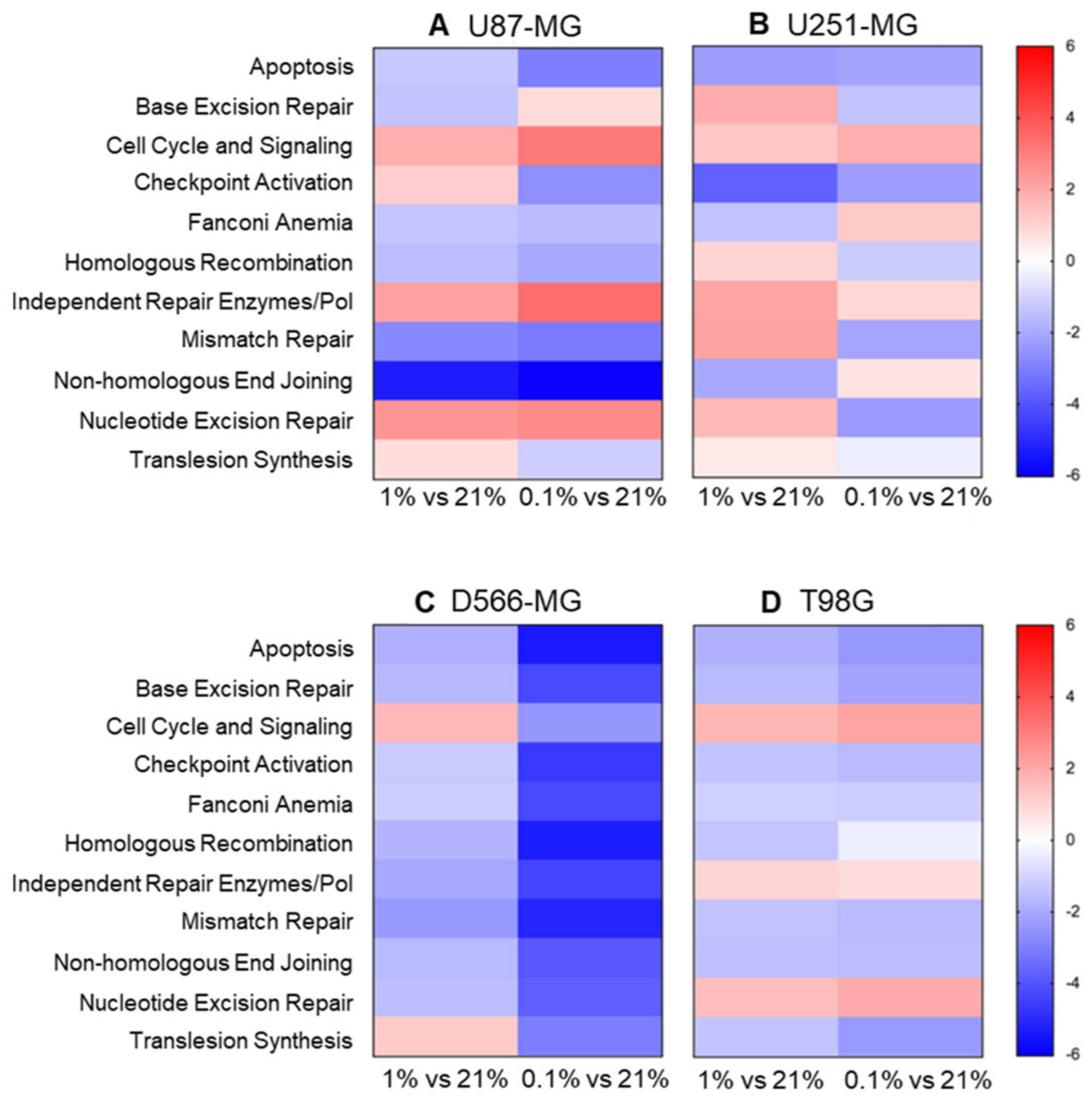




\section{Figure 2}

DNA repair gene regulation by hypoxia is observed across all GBM cell lines.

Gene expression data for (A) U87-MG, (B) U251-MG, (C) D566-MG and (D) T98G in 1\% or $0.1 \% \mathrm{O}_{2}$ is represented as $\log _{2}$ fold change with respect to $21 \% \mathrm{O}_{2}$ for each gene, plotted with $\log _{10} p$-value. Each point represents the average of three experimental replicates. Green filled circles signify genes that have a $p$-value below the $p<0.01$ threshold (dotted line). Dashed line is at $p=0.001$. Grey hollow circles represent non-statistically significant genes. The top 5 statistically significant genes are identified with the gene name. 
A

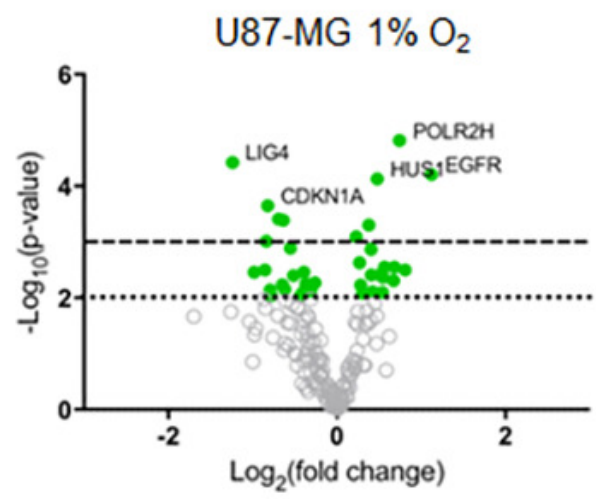

C

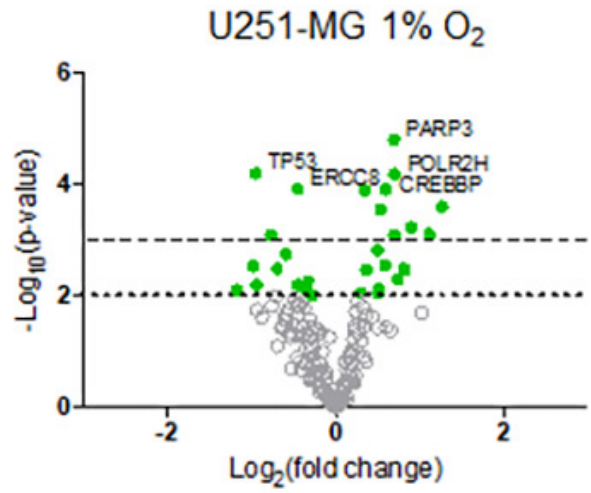

E

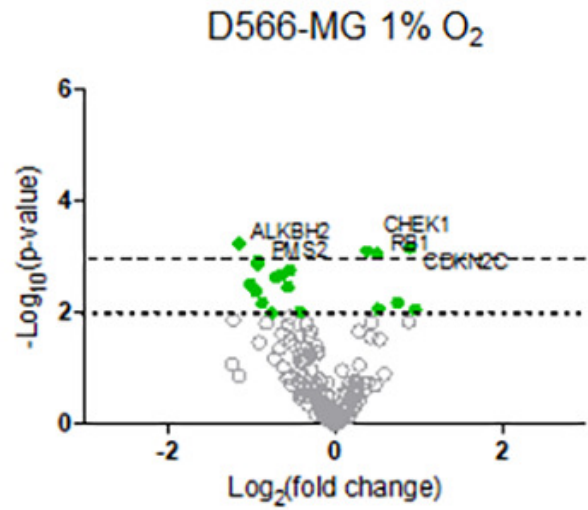

G

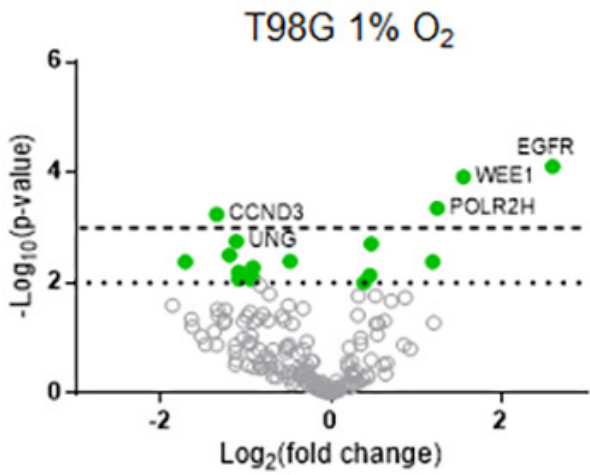

B

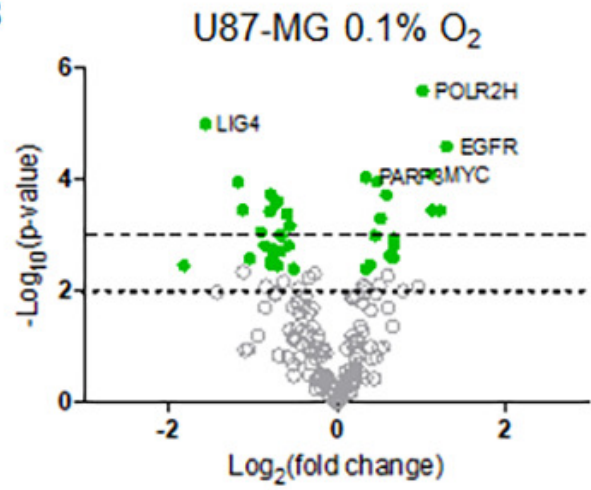

D

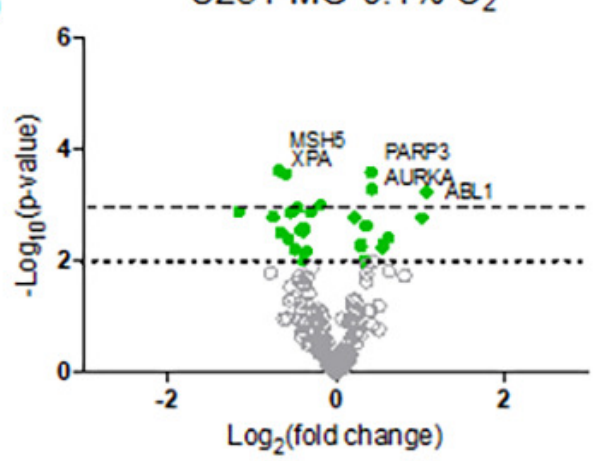

F

D566-MG $0.1 \% \mathrm{O}_{2}$

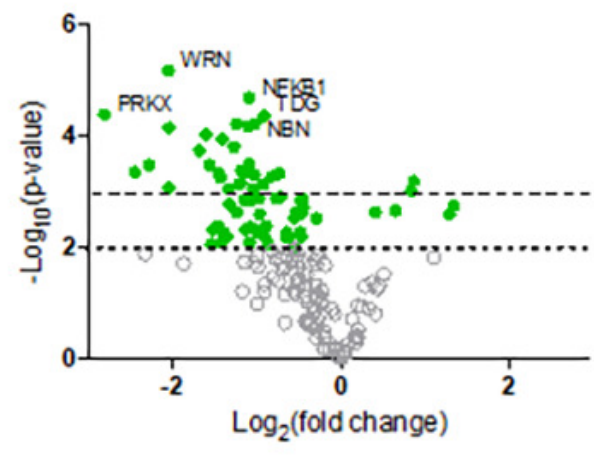

H

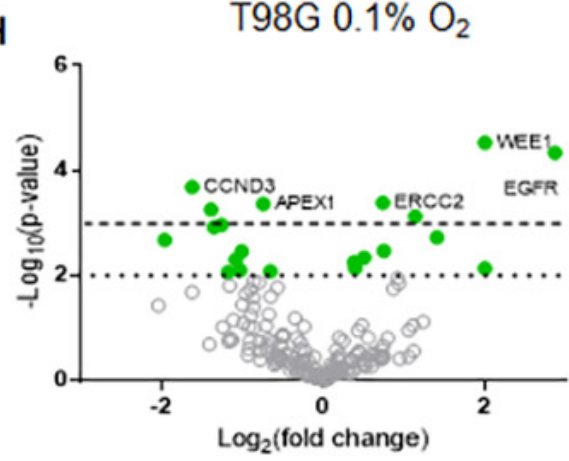




\section{Figure 3}

PMS2 and LIG4, essential components of MMR and NHEJ are downregulated in multiple cell lines.

Differential gene expression was calculated for each gene as $\log _{2}$ fold change for (A) MMR genes in $1 \% \mathrm{O}_{2}$, (B) MMR genes in $0.1 \% \mathrm{O}_{2}$, (C) NHEJ genes in $1 \% \mathrm{O}_{2}$, and (D) NHEJ in $0.1 \% \mathrm{O}_{2}$, with respect to the expression level at $21 \% \mathrm{O}_{2}$. Red shaded area denotes fold change values below the $+/-0.58 \log _{2}$ fold $(+/-1.5$-fold) threshold of change. Blue area denotes fold change values above the designated threshold. Filled shapes represent data which is statistically significant $(p<0.01)$, whereas hollow shapes show no statistical significance. Data are represented as the mean of three independent experiments. 


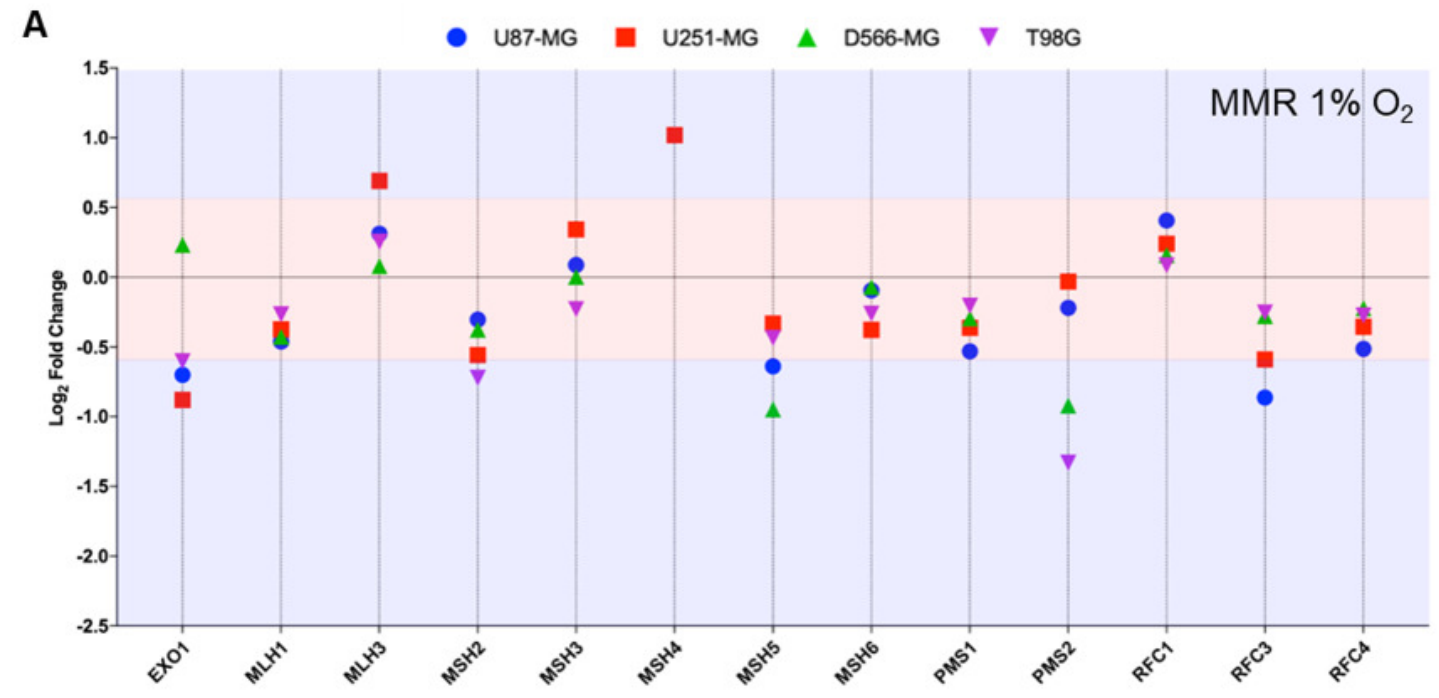

B

- U87-MG U U251-MG $\Delta$ D566-MG $\quad \nabla \quad$ T98G



C

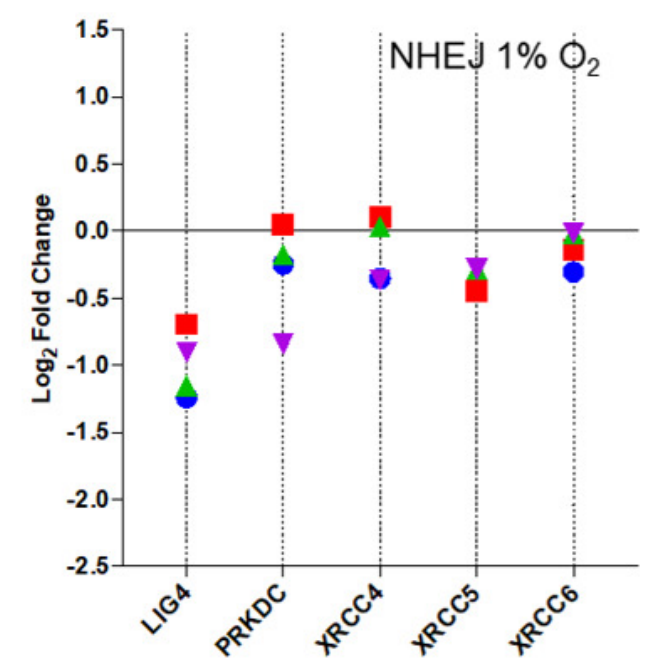

D

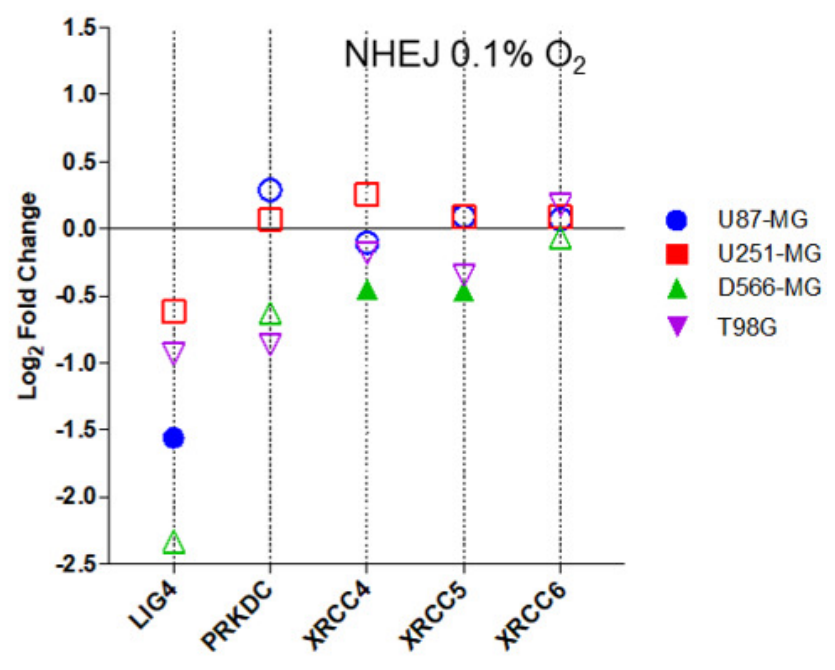




\section{Figure 4}

PMS2 and LIG4 are downregulated after acute and chronic hypoxic exposure.

(A) D566-MG cells were incubated in $1 \% \mathrm{O}_{2}$ for $1-5$ days, as well as $21 \% \mathrm{O}_{2}$. After incubation, RNA was extracted and converted to CDNA for RT-PCR experiments, probing for LIG4 and PMS2. Data is represented as $\log _{2}$ fold change in mRNA levels with respect to level for the $21 \% \mathrm{O}_{2}$ samples. Data are the mean of at least three independent experiments, with error bars showing S.E.M. * denotes significant data where $\mathrm{p}<0.05$ indicated by one-way student ttest. (B) Western blot of PMS2 in D566-MG and U87-MG cells, incubated in $21 \%, 1 \%$ or $0.1 \%$ $\mathrm{O}_{2}$ for 5 days. $\beta$ actin was used as a loading control. Experiments were performed in triplicate, a representative blot is shown. 
A

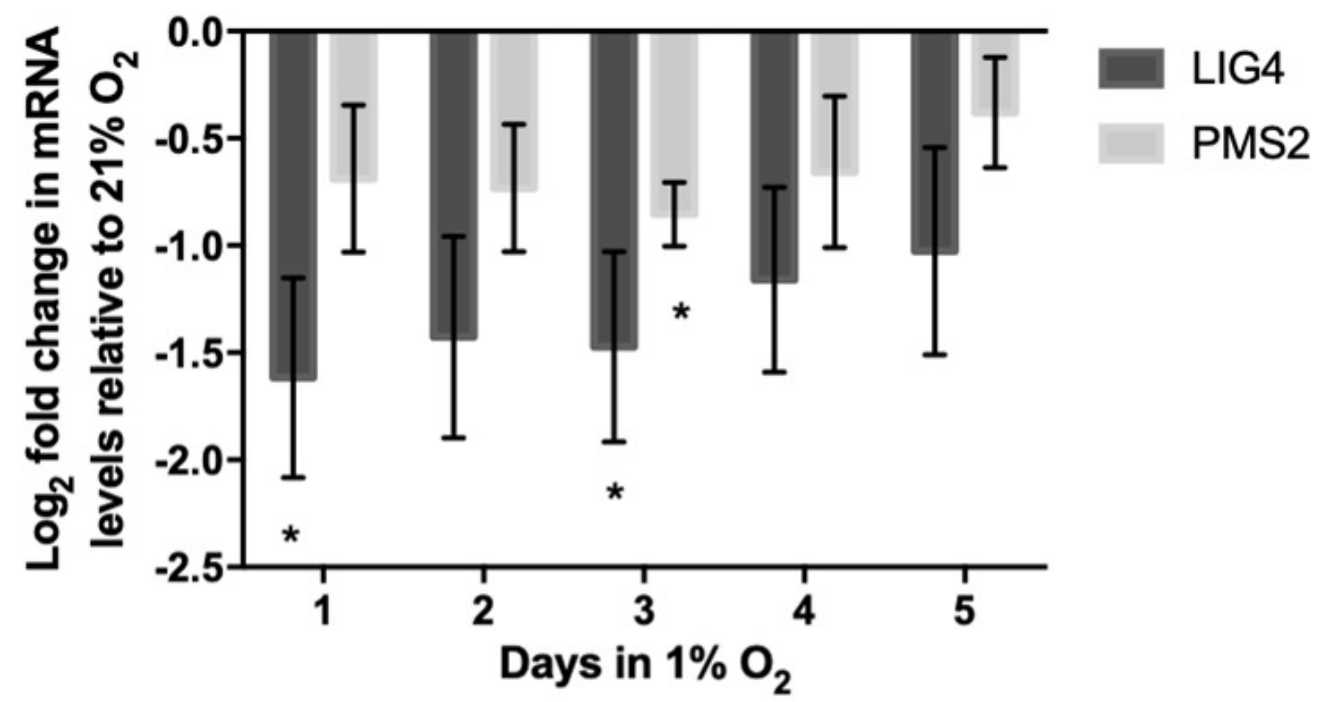

B

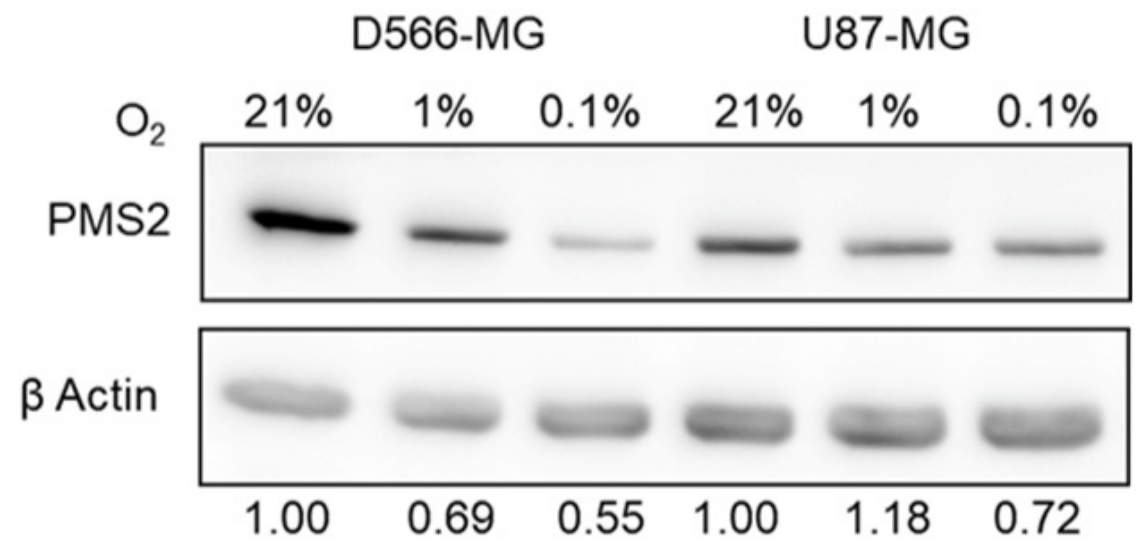




\section{Figure 5}

HIF inhibition by Acriflavin restored LIG4 downregulation.

(A) HIF-1 $\alpha$ and HIF-2 $\alpha$ are upregulated in chronic hypoxia. U87-MG and D566-MG cells were incubated in $1 \% \mathrm{O}_{2}$ and $21 \% \mathrm{O}_{2}$ for 0-120 h. Protein was extracted and the levels of HIF-1 $\alpha$ and HIF-2 $\alpha$ determined by western blotting in two independent experiments. A representative blot is shown with quantification of the bands, normalised to T0 (B) D566-MG and U87-MG cells were incubated in $21 \%$ and $1 \% \mathrm{O}_{2}$ for $24 \mathrm{~h}$ with and without $5 \mu \mathrm{M}$ Acriflavin. LIG4 mRNA levels were measured by RT-PCR. Data are represented as $\log _{2}$ fold change in mRNA levels with respect to $21 \% \mathrm{O}_{2}$ samples. Data are the mean of at least three independent experiments, with error bars showing S.E.M. 
A
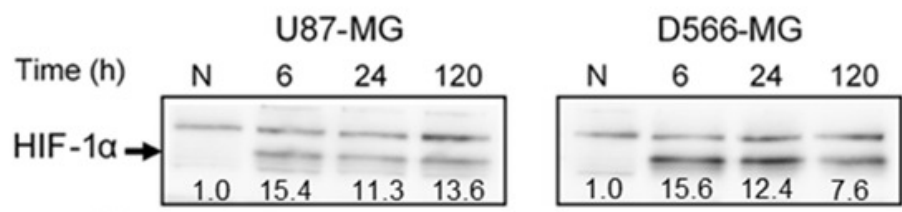

HIF-2 $\alpha$
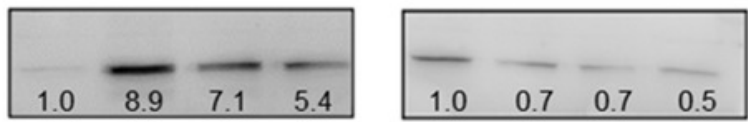

$\beta$ Actin
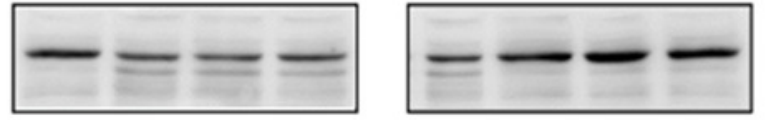

B
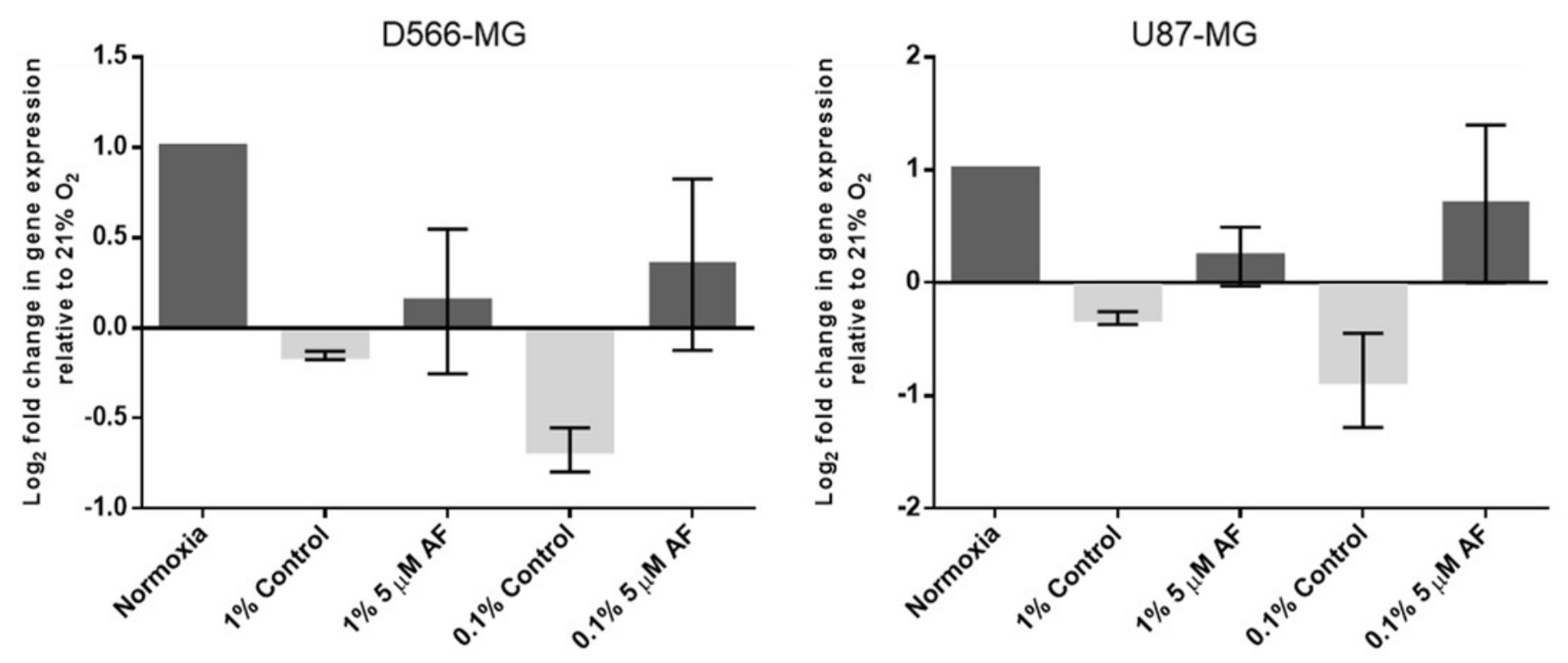